\title{
Why Some Students Continue to Value Individual, Face-to- Face Research Consultations in a Technology-Rich World
}

\section{Trina J. Magi and Patricia E. Mardeusz}

\begin{abstract}
For decades, academic librarians have provided individual research consultations for students. There is little information, however, about why students schedule consultations, the kinds of assistance students feel are provided by librarians during consultations, and what students find valuable about face-to-face consultations, even with the availability of online research help. This exploratory, qualitative study of individual research consultations at the University of Vermont gathered students' views on these questions. The findings will help librarians better understand how individual consultations serve students and what role consultations should play in the mix of reference services offered.
\end{abstract}

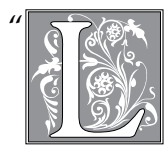

iving on the verge in the land of almost" - that's how one frustrated University of Vermont student described her feelings about her research project, even though she had access to the Web, hundreds of subscription databases, 1.5 million library books, 45,000 journal subscriptions and interlibrary loan services. After meeting with a librarian, she indicated her feeling had changed to "excited," testimony to the enduring power of the reference interaction to help students navigate the vast and complex information landscape.

With the development of new modes of communication, librarians are trying to sort out the places and ways they should deliver reference services - at service desks, in residence halls and other campus buildings, and via telephone, e-mail, chat, text messaging, and course management systems. ${ }^{1}$ Librarians also provide individual research consultations, a form of reference service in which the librarian meets individually with a student (or several students who are working together on a group project) in a scheduled session away from the reference desk. In recent years, the demand for such consultations has increased significantly at the University of Vermont.

As reference librarians make decisions about what mix of services to offer, it would serve them well to understand what each mode offers - what happens during encounters, and what students value about each. This is especially true 
in the academic library, where the goal of reference is to not only deliver answers to users' questions, but also to teach users how to frame their inquiries, select good sources, and to find, evaluate, and apply information. This exploratory study adds to the literature on reference services by investigating students' views about the content and value of individual research consultations.

\section{Literature Review}

The proliferation of communication technology has led librarians to experiment with a variety of channels for providing reference service. The reference encounter is no longer limited to face-to-face interactions at the reference desk but includes transactions conducted using telephone, e-mail, instant messaging, call centers, and texting. ${ }^{2}$ Many libraries publish online subject and research guides. ${ }^{3}$ Academic libraries also have offered individual consultations as a way for students to get in-depth research assistance away from the reference desk, where the librarian can focus exclusively on the student's needs. ${ }^{4}$ Faced with so many choices for service delivery, reference librarians must decide whether to use all these communication channels or some combination of them.

Views on how reference service should be delivered are many and diverse. Some writers argue that reference service should be phased out altogether. ${ }^{5}$ In recent years, libraries have eliminated reference desks, ${ }^{6}$ reinstated them, ${ }^{7}$ and created merged service points. ${ }^{8}$ Many have added texting and instant messaging or "chat" reference to their service mix; at the same time, other libraries are reporting surprisingly low preference for or use of such services. ${ }^{9}$ Ross and Sennyey claim that, in the digital environment, reference librarians are an obstacle that creates "friction" on the path to accessing information, and that emphasis should be placed on designing better computer interfaces as the best way to meet patron needs. ${ }^{10}$
In contrast, other writers have made claims about the ways in which human interaction-especially face-to-face interaction-is helpful, and together they provide a long list of benefits. Interaction with a librarian helps students frame their questions and provides additional perspectives, subject knowledge and problem-solving skills. ${ }^{11}$ It allows for the exchange of verbal and visual cues ${ }^{12}$ and provides students the opportunity to observe good research process and see first-hand the value of taking time to think about an assignment before searching. ${ }^{13}$ It allows librarians to transmit interpersonal, relational messages of empathy and interest found to be important to students ${ }^{14}$ and builds rapport between librarians and students. ${ }^{15}$ Ford found that more instruction occurred in face-to-face reference interactions compared to those that were computer mediated. ${ }^{16}$ Finally, there is evidence that college students believe librarians add value to the search process ${ }_{1}^{17}$ and that, counter to expectations, many students still want and even prefer face-to-face, personal help. ${ }^{18}$

One way to provide that face-to-face, personal help is through individual research consultations. In 2001, Cardwell, Furlong, and $\mathrm{O}^{\prime}$ Keeffe reported a dearth of articles about consultation services, with most being descriptions of individual programs, not studies. ${ }^{19}$ For example, Rowe explains how librarians at University of West Florida integrated consultations into a four-step bibliographic instruction program that also included group instruction. ${ }^{20}$

Since 2001, several authors have published additional articles describing their libraries' consultation services. Hoskisson and Wentz describe the implementation of a Term Paper \& Research Assistance service at Utah State University and report anecdotally on student response. ${ }^{21}$ Cardwell, Furlong, and O'Keeffe examine personalized research clinics at three institutions and report on logistics, publicity methods, rates of participation, and student feedback. ${ }^{22}$ Yi believes that 
the brief reference encounter and standalone library instruction program can no longer meet the demands generated by the information age and recommends that academic librarians revisit the use of individual research consultation services to fill the gap. ${ }^{23}$ Yi discusses the implementation of such a service at California State University San Marcos and its contributions to the information literacy program. Lee analyzes data from a year's use of the research consultation service offered at Mississippi State University to identify the client base and explore marketing strategies. ${ }^{24}$ Gale and Evans describe a consultation service implemented at Missouri State University. ${ }^{25}$ They report the results of a quantitative survey of student participants and a qualitative questionnaire about librarians' satisfaction with the service and their perceptions of its value and effectiveness.

Librarians acknowledge some concern about the seeming inefficiency of individual research consultations ${ }^{26}$ but also identify three chief advantages of providing reference service in this way: 1) Librarians are able to spend more time meeting student needs in a relaxed, private environment; ${ }^{27}$ 2) Librarians have the opportunity to prepare for the student interaction by reviewing resources or consulting with colleagues;, ${ }^{28}$ and 3) Librarians have greater opportunity to teach students skills for working independently on future projects. ${ }^{29}$ Gale and Evans outline additional benefits of consultations and note a renewed interest in the service, saying, "In a rush to embrace new methods of reaching their patrons such as virtual reference, online tutorials, video tutorials, wikis, etc., librarians must remember the power of face-to-face services and instruction provided at the point of need." 30

The above-cited articles provide examples of consultation programs, the views of librarians engaged in such programs, and a small amount of data about the students who participate. The current study builds on this literature by seeking more input from students who schedule individual research consultations, and it offers an in-depth look at why students schedule consultations, what happens during the consultations, and why the students who use them find them valuable.

\section{Research Questions}

The study sought to answer the following research questions:

1. How do students know to schedule a research consultation?

2. What motivates students to schedule a research consultation?

3. What kinds of assistance do librarians provide to students during research consultations?

4. What do students who use individual consultations find valuable about face-to-face interaction with librarians, even with the availability of online research help?

\section{Methodology \\ Approach}

The study was conducted at the University of Vermont using a qualitative approach, appropriate for an exploratory investigation. The study was granted exempt status by a representative of the university's Institutional Review Board and was conducted by two reference librarians (the authors) in the Information and Instruction Services Department at Bailey/ Howe Library. The University of Vermont enrolls about 10,500 undergraduate and 1,500 graduate students.

\section{Target Population}

During the spring semester 2011, all undergraduate and graduate students who received individual consultations with either of the authors were invited to participate in the study. No special efforts were made to publicize the consultation service or to recruit participants. Invitations to participate were made without regard to the students' topics or the librarians' assessment of the effectiveness of a particular consultation. 
University of Vermont students may request consultations by completing a form on the library's website. A coordinator then asks the appropriate subject-liaison librarian to respond. Most students, however, request consultations by contacting librarians directly. Students learn librarians' names through library instruction sessions, reference desk interactions, and through referrals from faculty members, friends, and other librarians. Librarians, therefore, may assist with any topic, but tend to provide more consultations in their assigned subject areas. The authors serve as liaisons to the following departments and programs: business, community development and applied economics, English, film and television studies, honors college, public administration, and theatre.

\section{Data Collection}

Data were collected using an anonymous survey administered on a computer in each librarian's office immediately following the consultation, while the librarian left the room. Students were given the option to speak their answers into a digital recorder instead, but none chose to do so. The survey included open-ended questions about why the consultation was sought, what kind of help the librarian provided, and whether or not it was valuable. It also asked students to name their major and academic status (for example, first-year, sophomore), and to answer several questions about how they knew about the consultation service and their likelihood of using it again and recommending it to others. Students were encouraged to be detailed and honest in their responses and were told not to worry about spelling, grammar, and punctuation. After the first nine students had completed the survey, the authors reviewed the responses to see if the survey questions were eliciting enough detail to be informative, and one open-ended question was added to gather additional data about why students chose consultations over other modes of getting help. The authors also kept logs in which they recorded the topic and length of each consultation.

\section{Data Analysis}

Descriptive statistics were used to show the number of consultations and length and to create frequency distributions for the following: students' majors and academic status; how students learned about the individual consultation service; and students' ratings of the value of consultations and their likelihood to use the service again and recommend it to others. The authors used content analysis to evaluate 12 pages of student responses to the open-ended survey questions. To achieve a more objective analysis, the authors first worked independently, studying the student responses to each question and making lists of themes that emerged. Then they reviewed and discussed each other's work and agreed on language to express the themes identified. Because this was an exploratory study to investigate what transpires during research consultations and to identify the ways in which consultations are valuable to students who use them, these themes are not reported in quantitative terms. Rather, they are listed and illustrated by quotations from the students.

\section{Limitations}

While this study gathered a large amount of data about students' accounting of what goes on during research consultations and about why consultations are valuable to the students who use them, it did not assess the effectiveness of consultations in terms of student learning outcomes. It does not compare this mode of reference service with others or measure the preferences of all students for the various modes of reference.

\section{Respondent Profile}

The authors conducted 44 individual consultations involving 53 students enrolled at the University of Vermont in the spring 2011 semester. For some sessions, more than one student was present. During the 


\begin{tabular}{|l|c|c|}
\hline \multicolumn{3}{|c|}{ TABLE 1 } \\
How Students Knew They Could Schedule Consultations* \\
\hline & Number & Percent \\
\hline The professor of my class suggested it & 26 & 51 \\
\hline The librarian I met with talked about it during her/his visit to my class & 19 & 37 \\
\hline A friend/classmate recommended it & 6 & 12 \\
\hline I have used this service before & 6 & 12 \\
\hline My advisor suggested it & 4 & 8 \\
\hline Someone at the library reference desk suggested it & 3 & 6 \\
\hline I read about it on the library website & 2 & 4 \\
\hline Other & 3 & 6 \\
\hline $\begin{array}{l}\text { *n-51; "number" and "percent" add up to more than 51 and 100 respectively because some } \\
\text { respondents selected more than one response. }\end{array}$ & \\
\hline
\end{tabular}

study period, members of the Information and Instruction Services Department provided 164 consultations, so the study respondent group represents 27 percent of that total. Sessions ranged in length from 30 to 90 minutes with an average of 59 minutes. Of the 53 students invited to take the survey, 52 agreed to do so. Forty-one percent of the respondents were seniors, 25 percent were juniors, 6 percent were sophomores, 20 percent were first-year students, and 8 percent were continuing education or graduate students.

In this study, 16 majors from six colleges at the university were represented in the respondent pool (see Appendix A). The consultations covered a wide range of research topics such as:

- Mary Queen of Scots and court entertainment

- Islamic influence on Spanish drama
- Comparing Thoreau and Kerouac through the lens of ecocriticism

- Nutritional needs for engaging in wilderness activities

- Good agricultural practices and dairy policy

- Sports/athletics and the human life cycle

- Intellectual property rights and China

- Demographics and marketing data about woodworkers

\section{Results and Analysis}

Research Question 1: How do students

know to schedule a research consultation?

Students were asked "How did you know you could schedule a consultation with a librarian?" As shown in table 1, referrals from their professors and promotion of the service by librarians visiting classes

\section{TABLE 2}

\section{What Motivates Students to Schedule Consultations}

1. Needed information or sources; had questions about using a specific resource

2. Needed help identifying search terms and developing search structure

3. Were unsuccessful finding information on their own, or had reached a "roadblock" and needed more

4. Wanted to make sure they knew about resources available to them

5. Didn't know where to start; needed a plan; needed direction or organization

6. Had concerns and questions about assignment or topic

7. Wanted access to the expertise of a librarian

8. Were required or advised by instructor to meet with a librarian 
yielded the vast majority of consultations. Prior use by students and the recommendation of friends and classmates also played a notable role.

\section{Research Question 2: What motivates students to schedule a research consultation?}

Students were asked, "What was going on with your research project that made you decide to schedule a meeting with the librarian?" Their responses reflected eight themes, shown in table 2.

Although a few students indicated their professors required them to schedule consultations, each of these students articulated an additional reason of their own. Not surprisingly, the motivating factor most frequently cited by students (more than a third) was the need for help finding information and choosing and using resources. Some students expressed the need for specific types of sources (such as scholarly articles, newspaper articles, parole board hearings, statistics), and others were explicit about their desire for high-quality information - wanting to find "good," "best," "credible," "reliable," and "most valuable" sources. A couple students specifically said they needed help with search terms or structure. For example, "I wasn't sure how to create searches that would yield the most valuable sources." A number of responses indicate that students scheduled consultations because they recognized the expertise and subject knowledge of librarians and wanted to take advantage of it. For example, "I heard [the librarian] speak about marketing in my Strategic Planning class and I really wanted to utilize her knowledge to make our event a great success."

Survey responses make it clear that many students (almost a third) already had attempted to find information on their own before their consultations and had run into various roadblocks and challenges. As two students explained: "I kept coming up with an abundance of articles but they were either way to [sic] specific of [sic] case studies or they weren't relevant at all," and "I also didn't know how to find different articles. The same ones kept coming up."

A handful of students, including new students, said they scheduled a consultation not because they were having trouble but to be sure they were taking full advantage of all the resources the library has to offer. For example, "Just started as a grad student at UVM and I wanted to talk to the librarian about resources available for my research."

In addition to wanting help with the process of finding information, students needed help with broader research concerns. Many said they didn't know where to start and needed help planning and organizing their work (for example: "I needed to make a research plan of what materials I was going to use, and what direction I was taking,

\begin{tabular}{|ll|}
\hline \multicolumn{1}{|c|}{ TABLE 3} \\
& \multicolumn{1}{c}{\begin{tabular}{c}
\multicolumn{1}{c}{ Students' Accounting of the Kinds of Assistance Provided by Librarians } \\
During Consultations
\end{tabular}} \\
\hline 1. & Selecting and recommending sources \\
2. & Searching the catalog and databases \\
3. & Identifying search terms \\
4. & Helping to understand the assignment or task \\
5. & Determining concept areas; determining what to include in paper; developing and \\
6. & Developing a research strategy \\
7. & Teaching how to use data and information and determine if it's credible \\
8. & Using the library facility and services \\
9. & Reducing stress and providing encouragement and other affective benefits \\
10. & Sharing librarian's subject knowledge \\
\hline
\end{tabular}


and I wasn't sure where to start."). Other students had concerns about their assignments or topics (for example: "I did not have a clear focus to my thesis or even know where to begin asking questions about how to narrow it," and "This project assignment is super vague and there isn't a whole lot of direction from the professor, so I needed help in finding resources on the topic that my group chose.").

\section{Research Question 3: What kinds of assistance do librarians provide to students during research consultations?}

Students were asked, "What kinds of things did the librarian try to help you with?" Their responses fell into 10 categories, listed in table 3.

The vast majority (almost three quarters) of students indicated the librarian helped them by selecting and recommending sources, including databases and reference books, and brainstorming about places to search. Almost a third said the librarian taught them how to search the catalog and databases, teaching search techniques such as truncation, and one third said the librarian helped them identify search terms. For example, students said librarians helped by "Guiding my research. Sharing resources. Idea sharing. Brainstorming...I will leave with a better understanding and asking the right questions"; and "Find specific synonyms for my topic, find relevant databases to search, try multiple combinations."

Many students said the librarian helped them understand their teachers' assignments, clarify their topics and identify concept areas within those topics, and develop a research strategy: "She helped us a [sic] teacher's assignment and really break it down to where the questions were answerable using the resources she provided...I feel like I am able to start the project now"; "...gave me a few pointers in what to look for in my topic"; and "Providing a strategy to begin the research process."

A few students said that, in addition to helping them find information, the librarian provided instruction in using the information and determining whether it was reliable and relevant to their projects (for example: "She helped me understand... how I could possibly use the things I found in forming my paper."), and, in a few cases, students indicated the importance of the librarian's subject knowledge (for example, "she went through all the different types of marketing techniques and came up with ideas that we could use for each one. she also came up with great ideas of people to contact to help promote the event.").

Students reported that during the course of the consultation, the librarians provided them with useful information about using the library's services and physical spaces. For example: "Also explained how to use the stacks of journals here, as well as retrieving books from the annex"; "Showed me how to use interlibrary loans..."; and "...different parts of the library did not know about..."

Many students wrote about affective benefits such as feelings of increased confidence and reduced stress, as illustrated by the following: "I without doubt feel more confident in going about my research now that I had an individual consultation with a librarian"; "Helped both of feel [sic] less stressed out and overwhelmed. She was VERY helpful and I honestly wish I had come to her before I was a senior in my last semester of college. I will recommend it to everyone I know working on assignments"; and "It was just as [sic] helpful and 'destressing' to just have a sounding board..."

\section{Research Question 4: What do students who use individual consultations find valuable about face-to-face interaction with librarians, even with the availability of online research help?}

Data about the value of consultations were gathered from students using 1) three closed-ended survey questions, 2) two open-ended survey questions, and 3) an exercise that asked students to label their pre- and post-consultation feelings about their research projects. The results are reported below.

\section{Intention to Use Consultation Service} Again, and Intention to Recommend When asked whether or not they thought 
it was valuable to have a face-to-face individual consultation with a librarian, all 52 respondents said "Yes." All respondents also said they would use the consultation service again, with 88 percent saying "definitely" and 12 percent saying "probably." When asked how likely they are to recommend the consultation service to a friend or classmate, all respondents answered either that they definitely would recommend (92 percent) or probably would recommend (8 percent).

\section{Ways in Which Face-to-Face}

Consultations Are Valuable to Students

Students answered two open-ended questions: "Please list or describe the reason(s) you think it's valuable to have an individual consultation," and "What was appealing to you about a face-to-face meeting with a librarian, given the availability of other ways of getting research help (such as using online research guides or asking a question using e-mail reference or chat/ IM reference)?" Their responses revealed eight reasons, shown in table 4.

Many students wrote about the value of individual consultations by stating that they are a quick, easy, and efficient way to get research help, compared to e-mail or chat. This is somewhat surprising, given that students had to request an appointment with a librarian and sometimes wait one to three days for the meeting. This is how three of these students explained it: "It is easier to understand things when working face to face, questions and answers can be exchanged faster..."; "An hour and a half of real world interaction about a topic cannot be reproduced via email, at least $i$ can't imagine it!"; and "Those ways [e-mail or chat] are not very useful, are stressful and time consuming."

Students frequently pointed out how in-person interaction allowed them to see how the librarian goes about searching and finding materials, enabling them to replicate the process later. Several students specifically mentioned that faceto-face help was useful in learning to navigate websites. These students are quite self-aware in recognizing what mode of interaction works best for them. For example: "I am a visual learner-I understand much much more by watching a librarian perform searches than reading about it via email"; "...I learn better in person and through discussion rather than online, different learning style"; and "...also, if I am confused she can pick that up in my facial expressions and will work to make sure I understand."

Students also said face-to-face consultations are valuable because they enable them to collaborate with another person who has expertise and experience-either to "bounce" ideas off them, or to get help finding resources they couldn't find on their own. For example: "I needed another opinion on my personal situation; a computer

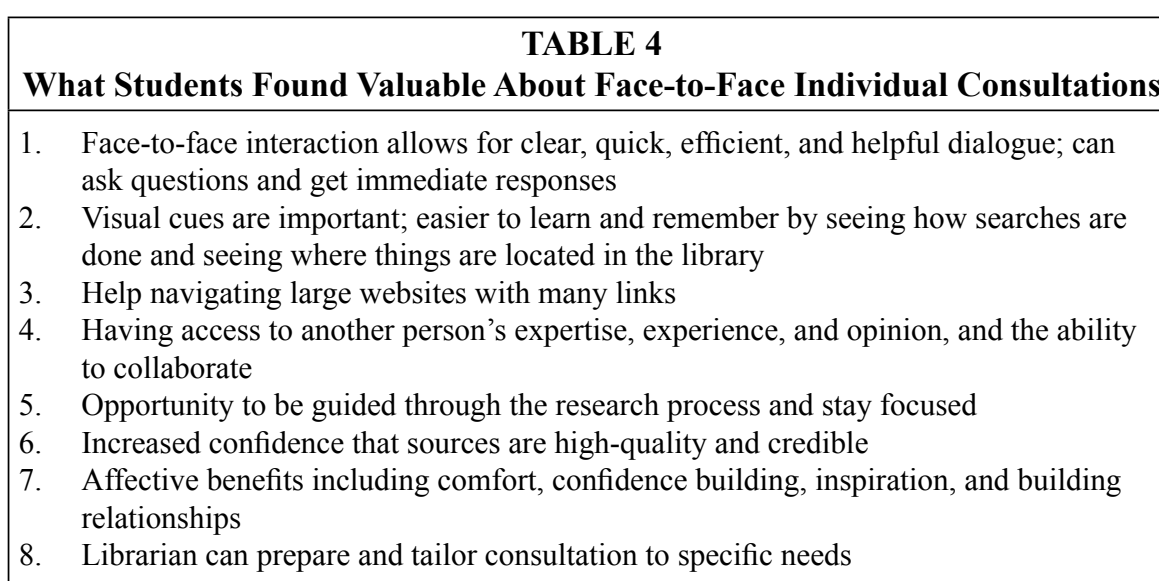


can only tell you so much"; " ... the more I have to articulate to someone what it is I'm trying to do with the research, the more I' $m$ able to work it out in my own head"; and "Meeting with a librarian is helpful because they know the books from experience and have great advice on what is useful..."

Individual consultations were valuable to many students because they needed someone to guide them through the research process in relation to their assignments (for example: "The one-onone personal help really allowed me to ask questions, and help me outline the steps I needed to follow in order to complete my thesis proposal."). Students also find value in the fact that meeting with a librarian "forces" them to focus (for example, "Have a much higher tendency to pay attention and take in the useful information.").

Students' concerns about credibility of sources emerged again in relation to these questions. A face-to-face meeting with a librarian seems to give students confidence that they are accessing highquality sources (for example: "She helped me by explaining why some sources are more reliable than others.").

Many students wrote about the value of face-to-face consultations in terms of affective benefits. They clearly appreciated being reassured and inspired, and they have a desire to build relationships. For example: "It's very calming to know someone is there who's seen it before and that your own problems are not atypical"; "... the energy one gets from working with somebody else can be a lot more motivating than just emailing"; and "It allowed me to have a personal relationship with someone who could help me a great deal."

Finally, students also noted that scheduling an individual consultation allows the librarian to prepare and tailor the session to the student's need (for example: "...she put in a ton of effort on my behalf before our meeting which was unexpected and super helpful!"). Students appreciate that this advance work makes it possible to have a more substantive conversation about their projects (for example: "[The librarian] was able to tailor the consultation specifically to me [sic] needs and we were able to have a discussion.").

\section{Students' Feelings about Their Research Projects before and after the Consultation}

At the beginning of each consultation, the student was asked to think of a word or phrase to describe how he/she was feeling about his/her research project. The student was instructed not to tell the librarian but rather to record the word or phrase on the survey at the end of the session. The single most frequently chosen word was "overwhelmed," given by more than a third of the respondents. The next most common feeling was anxiety, expressed by such words as "anxious," "nervous," worried," "concerned," "stressed," and "uneasy" (about 20 percent of respondents). Other responses included: "Lost," "Frustrated," "Scattered," "Didn't know where to start," "Staring into the unknown," "Irritated," "Pretty confident, but willing to learn more," and "Living on the verge in the land of almost."

Students also were asked to think of a word or phrase to describe how they were feeling after the consultation. All but one respondent noted a change for the positive (he or she was "anxious" before and "nervous" after). Most students reported feeling "relieved," "confident," "prepared," "ready to work," "organized," and even "super excited" about their research projects after the consultations. A few students used language indicating that the consultation helped them more clearly realize their needs or inspired them to think more deeply about their project (for example: "more self-imposed direction," "intrigued," "want to explore more about my project"). (See Appendix B for a complete list.)

\section{Conclusion}

At the University of Vermont, the annual number of individual research consultations has increased by 39 percent from $2004 / 2005$ to $2010 / 2011$, even as other modes of reference service were added. 
This exploratory, qualitative study of individual consultations yielded a wealth of data from students about what happens during consultations and why they are of value to the students who use them.

The study found that students learned about the consultation service mostly from their professors and from librarians who visited their classes. The service attracts students across the spectrum of subject knowledge and research ability-from novices to experts. Students seek consultations for a variety of reasons, from not knowing how to start their research to making sure they have used all the resources to the fullest, and their projects ranged from very simple to multifaceted and complex. Before the consultations, many students had made research efforts and had encountered roadblocks, with some indicating frustration with the fact that their searches lacked precision and they were unable to find relevant materials.

The data show that many different activities happen during consultations. As expected, students reported getting help with choosing databases, identifying keywords, and using search interfaces - the skills that some librarians claim will become less important with advances in search interface design and the implementation of new discovery tools. It's important to note, however, that students named many other ways the librarians helped them, including interpreting their professors' assignments, brainstorming about how to approach their projects, discussing possible topics, sharing knowledge about the subject, evaluating results for relevance and credibility, determining how disparate pieces of information could be used in a paper, and providing advice about how to stay organized during a semester-long research project-all tailored to the individual student's needs. It is impossible to imagine how even vastly improved database interfaces could provide this breadth and depth of information literacy instruction.

Students who participated in consultations were unanimously positive about their value, and they indicated great likelihood to use the service again and recommend it to others. Students' responses show they recognize and appreciate gaining access to the expertise and knowledge of librarians and that working with a librarian helps students feel more comfortable about the credibility of information sources. In addition, affective benefits of face-to-face communication are important to these students. Many stated that the consultation was valuable because it helped relieve their anxiety and feelings of being overwhelmed and made them feel encouraged, more focused, and even inspired. Students also appreciate the chance to build relationships with librarians, a finding that was affirmed by the fact that numerous students voluntarily kept in touch with the librarians after their consultations to report on their progress or the outcome of their projects.

Somewhat surprising is the fact that many students described the individual consultation as a more quick, easy, and efficient way to get help, compared to using e-mail or chat reference. They also reported that watching the librarian work through a problem helps them learn and later replicate the research process. This suggests that students appreciate the richness of face-to-face communication and value the opportunity for dialogue, collaboration, and exchange of nonverbal informationall of which efficiently steer the interaction in the most helpful direction.

Each mode of reference service delivery offers particular advantages for the user or the librarian. This study revealed the depth and richness of individual research consultations and the reasons why some students continue to find them valuable. Reference librarians who are concerned about giving students the opportunity to deeply engage with their research projects and develop a wide range of information literacy competencies should make research consultations an important component in their mix of reference services. 


\section{Suggestions for Further Research}

The findings of this exploratory study suggest several directions for future research:

- Most students who used the consultation service learned about it from their professors. Do students who use librarian consultation services also visit faculty offices more frequently than do other students? How much library research assistance do these instructional faculty members provide before recommending that students contact librarians? Are the faculty members who recommend students to the library the least facile with library research themselves, or are they more likely to be expert library users who understand all that the library has to offer?
- Do students who use librarian consultation services have better educational outcomes than those who do not (such as better grades on their papers, higher gradepoint averages)?

- Why do so many students who seek librarian consultations need help understanding their professors' assignments? Why are they unable to get adequate clarification from their professors?

- To what degree do students who seek consultations also use other modes of reference service?

- Is student demand for consultations growing at other colleges and universities? If so, why, and how can librarians continue to meet that demand?

\section{APPENDIX A}

\begin{tabular}{|l|c|c|}
\hline \multicolumn{3}{|c|}{ Reported Majors of Participating Students } \\
\hline \multicolumn{2}{|c|}{$\begin{array}{c}\text { (n=51; number and percent add up to more than 51 and } 100 \text { respectively because } \\
\text { some respondents indicated two majors) }\end{array}$} \\
\hline Major & Number & $\begin{array}{c}\text { Percent of } \\
\text { Respondents }\end{array}$ \\
\hline Business Administration & 16 & 31 \\
\hline English & 10 & 20 \\
\hline Theatre & 5 & 10 \\
\hline Community Entrepreneurship & 4 & 8 \\
\hline History & 3 & 6 \\
\hline Psychology & 3 & 6 \\
\hline Community Development and Applied Economics & 2 & 4 \\
\hline Nursing & 2 & 4 \\
\hline Animal Science & 1 & 2 \\
\hline Anthropology & 1 & 2 \\
\hline Early Childhood Special Education & 1 & 2 \\
\hline Environmental Studies & 1 & 2 \\
\hline European Studies & 1 & 2 \\
\hline Medical Research & 1 & 2 \\
\hline Nutrition and Food Sciences & 1 & 2 \\
\hline Political Science & 1 & 2 \\
\hline
\end{tabular}




\section{APPENDIX B}

\begin{tabular}{|c|c|}
\hline \multicolumn{2}{|c|}{ Student Feelings before and after Consultations } \\
\hline Feelings before Consultation & Feelings after Consultation \\
\hline interesting & exciting \\
\hline overwhelmed & prepared \\
\hline unprepared & on my way \\
\hline stressful & relieved \\
\hline overwhelmed & enthusiastic \\
\hline good & very confident \\
\hline $\begin{array}{l}\text { stressed because of the vague idea of the } \\
\text { assignment }\end{array}$ & a little bit relieved, more confident \\
\hline overwhelmed & excited and intrigued \\
\hline lost & having a place to start \\
\hline scattered & thoughtful \\
\hline $\begin{array}{l}\text { scattered research-needing more terms to } \\
\text { really focus topic }\end{array}$ & more on track \\
\hline confused & relieved \\
\hline $\begin{array}{l}\text { overwhelmed, lost, confused, didn't know } \\
\text { where to start }\end{array}$ & relieved, focused \\
\hline pretty confident, but willing to learn more & ready for action! \\
\hline overwhelmed & excited \\
\hline overwhelmed & relieved \\
\hline overwhelmed & hopeful \\
\hline overwhelming & manageable \\
\hline confused & confident \\
\hline overwhelmed & better \\
\hline stressed & relieved \\
\hline reference & relaxed \\
\hline confused & relieved \\
\hline lost & confident \\
\hline overwhelmed & a better understanding \\
\hline worried & slightly less worried \\
\hline overwhelmed & more confident, a lot of work ahead of me \\
\hline overwhelmed & confident \\
\hline stressed & relaxed \\
\hline optimistic but a bit lost & confident \\
\hline overwhelmed & more confident \\
\hline overwhelmed & prepared \\
\hline uneasy & confident \\
\hline
\end{tabular}


Face-to-Face Research Consultations in a Technology-Rich World 617

\begin{tabular}{|l|l|}
\hline \multicolumn{2}{|c|}{ Student Feelings before and after Consultations } \\
\hline Feelings before Consultation & Feelings after Consultation \\
\hline overwhelmed & much better \\
\hline anxious & nervous \\
\hline $\begin{array}{l}\text { I was not entirely sure what to look for in } \\
\text { my project assignment }\end{array}$ & more confident \\
\hline excited & super excited \\
\hline living on the verge in the land of almost & excited \\
\hline staring into the unknown & welcomed to a new world \\
\hline lost & in need of more self-imposed direction \\
\hline challenging & more confident, lot of work ahead of me \\
\hline overwhelmed & organized \\
\hline anxious & confident \\
\hline $\begin{array}{l}\text { confident that I could do the research, but } \\
\text { worried about finding sources }\end{array}$ & $\begin{array}{l}\text { happy that there is research out there } \\
\text { relatively easy to access and feeling less } \\
\text { "stuck" }\end{array}$ \\
\hline overwhelmed & confident \\
\hline concerned & confident \\
\hline irritated & confident \\
\hline not done & started/initiated \\
\hline $\begin{array}{l}\text { overwhelmed, frustrated, concerned, not } \\
\text { excited }\end{array}$ & relief and ready to go! \\
\hline very frustrated & release \\
\hline nervous & $\begin{array}{l}\text { confident, ready to work, floating ideas, } \\
\text { want to explore more about my project }\end{array}$ \\
\hline felt good but wanted more in-depth sources & found more in-depth sources \\
\hline & \\
\hline
\end{tabular}

\section{Notes}

1. Sarah K. Steiner and M. Leslie Madden, eds., The Desk and Beyond: Next Generation Reference Services (Chicago: Association of College and Research Libraries, 2008).

2. Juris Dilevko, "An Ideological Analysis of Digital Reference Service Models," Library Trends 50, no. 2 (Oct. 15, 2001): 218-44; Thomas A. Peters, "Left to Their Own Devices: The Future of Reference Services on Personal, Portable Information, Communication, and Entertainment Devices," Reference Librarian 52, no. 1/2 (Jan. 2011): 88-97; Courtney Selby, "The Evolution of the Reference Interview," Legal Reference Services Quarterly 26, no. 1/2 (Jan. 2007): 35-46.

3. Bradley Brazzeal, "Research Guides as Library Instruction Tools," Reference Services Review 34, no. 3 (2006): 358-67.

4. Crystal D. Gale and Betty S. Evans, "Face-to-Face: The Implementation and Analysis of a Research Consultation Service," College \& Undergraduate Libraries 14, no. 3 (Jan. 3, 2007): 85-101; Iris Jastram and Ann Gwinn Zawistoski, "Personalizing the Library via Research Consultations," in The Desk and Beyond: Next Generation Reference Services, eds. Sarah K. Steiner and M. Leslie Madden (Chicago: Association of College and Research Libraries, 2008), 14-24.

5. Keith Ewing and Robert Hauptman, "Is Traditional Reference Service Obsolete?" Journal of Academic Librarianship 21, no. 1 (Jan. 1995): 3-6.

6. Theresa S. Arndt, "Reference Service without the Desk," Reference Services Review 38, no. 1 (Jan. 2010): 71-80.

7. Michele McCaffrey, St. Michael's College (telephone conversation with author, Dec. 12, 
2011).

8. Janet Crane and Jeanne A. Pavy, "One-Stop Shopping: Merging Service Points in a University Library," Public Services Quarterly 4, no. 1 (Apr. 2008): 29-45; Bing Wang and Bruce Henson, "Change Is Coming: A Combined Services Area Project," Science \& Technology Libraries 30, no. 1 (Mar. 2011): 89-98.

9. Lizah Ismail, "What Net Generation Students Really Want: Determining Library HelpSeeking Preferences of Undergraduates," Reference Services Review 38, no. 1 (Jan. 2010): 10-27; Sharon Naylor, Bruce Stoffel, and Sharon Van Der Laan, "Why Isn't Our Chat Reference Used More? Finding of Focus Group Discussions with Undergraduate Students," Reference \& User Services Quarterly 47, no. 4 (July 15, 2008): 342-54.

10. Lyman Ross and Pongracz Sennyey, "The Library Is Dead, Long Live the Library! The Practice of Academic Librarianship and the Digital Revolution," Journal of Academic Librarianship 34, no. 2 (Mar. 2008): 145-52.

11. Dilevko, "An Ideological Analysis," 218-44; Anne M. Fields, "Ill-Structured Problems and the Reference Consultation: The Librarian's Role in Developing Student Expertise," Reference Services Review 34, no. 3 (Jan. 3, 2006): 405-20.

12. Selby, "The Evolution of the Reference Interview," 35-46.

13. John M. Budd, "Cognitive Growth, Instruction, and Student Success," College \& Research Libraries 69, no. 4 (July 2008): 319-30; Fields, "Ill-Structured Problems," 405-20.

14. Marie L. Radford, "Encountering Users, Encountering Images: Communication Theory and the Library Context," Journal of Education for Library and Information Science 42, no. 1 (Dec. 15, 2001): 27-41.

15. Selby, "The Evolution of the Reference Interview," 35-46; Hua Yi, "Individual Research Consultation Service: An Important Part of an Information Literacy Program," Reference Services Review 31, no. 4 (Jan. 4, 2003): 342-50.

16. Charlotte E. Ford, "An Exploratory Study of the Differences between Face-to-Face and Computer-Mediated Reference Interactions" (PhD diss., Indiana University, 2002).

17. OCLC, "Perceptions of Libraries, 2010: Context and Community," available online at http://www.oclc.org/reports/2010perceptions/2010perceptions_all_singlepage.pdf [accessed 21 December 2011].

18. Caroline Cason Barratt, Phoebe Acheson, and Emily Luken, "Reference Models in the Electronic Library: The Miller Center at the University of Georgia," Reference Services Review 38, no. 1 (Jan. 2010): 44-56; Melissa Gross and Don Latham, "Undergraduate Perceptions of Information Literacy: Defining, Attaining, and Self-Assessing Skills," College \& Research Libraries 70, no. 4 (July 2009): 336-50.

19. Catherine Cardwell, Katherine Furlong, and Julie O'Keeffe, "My Librarian: Personalized Research Clinics and the Academic Library," Research Strategies 18, no. 2 (Jan. 4, 2001): 97-111.

20. Caroline E. Rowe, "Individual Research Consultations: A Safety Net for Patrons and Librarians," Southeastern Librarian 41 (Spring 1991): 5-6.

21. Tam Hoskisson and Deleyne Wentz, "Simplifying Electronic Reference: A Hybrid Approach to One-on-One Consultation," College \& Undergraduate Libraries 8, no. 2 (Jan. 2, 2001): 89-102.

22. Cardwell, Furlong, and O'Keeffe, “My Librarian," 97-111.

23. Yi, "Individual Research Consultation Service," 342-50.

24. Deborah Lee, "Research Consultations: Enhancing Library Research Skills," Reference Librarian no. 85 (Jan. 2004): 169-80.

25. Gale and Evans, "Face-to-Face," 85-101.

26. Rowe, "Individual Research Consultations," 5-6.

27. Cardwell, Furlong, and O'Keeffe, "My Librarian," 97-111; Fields, "Ill-Structured Problems," 405-20; Gale and Evans, "Face-to-Face," 85-101; Hoskisson and Wentz, "Simplifying Electronic Reference," 89-102; Jastram and Zawistoski, "Personalizing the Library," 14-24; Rowe, "Individual Research Consultations," 5-6; Yi, "Individual Research Consultation Service," 342-50.

28. Gale and Evans, "Face-to-Face," 85-101; Rowe, "Individual Research Consultations," 5-6; Yi, "Individual Research Consultation Service," 342-50.

29. Gale and Evans, "Face-to-Face," 85-101; Hoskisson and Wentz, "Simplifying Electronic Reference," 89-102; Jastram and Zawistoski, "Personalizing the Library," 14-24; Lee, "Research Consultations," 169-80; Yi, "Individual Research Consultation Service," 342-50.

30. Gale and Evans, "Face-to-Face," 89. 